\title{
ORIGINAL
}

\section{Extracorporeal membrane oxygenation in patients with severe respiratory failure from COVID-19}

Shahzad Shaefi ${ }^{1 *}$ (0, Samantha K. Brenner ${ }^{2,3}$, Shruti Gupta ${ }^{4}$, Brian P. O'Gara' ${ }^{1}$, Megan L. Krajewski', David M. Charytan" ${ }^{5}$, Sobaata Chaudhry, Sara H. Mirza ${ }^{6}$, Vasil Peev ${ }^{7}$, Mark Anderson ${ }^{8,9}$, Anip Bansal10, Salim S. Hayek ${ }^{11}$, Anand Srivastava ${ }^{12}$, Kusum S. Mathews ${ }^{13}$, Tanya S. Johns ${ }^{14}$, Amanda Leonberg-Yoo ${ }^{15}$, Adam Green ${ }^{16}$, Justin Arunthamakun ${ }^{17}$, Keith M. Wille ${ }^{18}$, Tanveer Shaukat ${ }^{4}$, Harkarandeep Singh ${ }^{4}$, Andrew J. Admon ${ }^{19}$, Matthew W. Semler ${ }^{20}$, Miguel A. Hernán ${ }^{21,22}$, Ariel L. Mueller ${ }^{23}$, Wei Wang ${ }^{24}$ and David E. Leaf ${ }^{4}$ on behalf of the STOP-COVID Investigators

(c) 2021 Springer-Verlag GmbH Germany, part of Springer Nature

\begin{abstract}
Purpose: Limited data are available on venovenous extracorporeal membrane oxygenation (ECMO) in patients with severe hypoxemic respiratory failure from coronavirus disease 2019 (COVID-19).

Methods: We examined the clinical features and outcomes of 190 patients treated with ECMO within 14 days of ICU admission, using data from a multicenter cohort study of 5122 critically ill adults with COVID-19 admitted to 68 hospitals across the United States. To estimate the effect of ECMO on mortality, we emulated a target trial of ECMO receipt versus no ECMO receipt within 7 days of ICU admission among mechanically ventilated patients with severe hypoxemia $\left(\mathrm{PaO}_{2} / \mathrm{FiO}_{2}<100\right)$. Patients were followed until hospital discharge, death, or a minimum of 60 days. We adjusted for confounding using a multivariable Cox model.

Results: Among the 190 patients treated with ECMO, the median age was 49 years (IQR 41-58), 137 (72.1\%) were men, and the median $\mathrm{PaO}_{2} / \mathrm{FiO}_{2}$ prior to ECMO initiation was 72 (IQR 61-90). At 60 days, 63 patients (33.2\%) had died, 94 (49.5\%) were discharged, and 33 (17.4\%) remained hospitalized. Among the 1297 patients eligible for the target trial emulation, 45 of the 130 (34.6\%) who received ECMO died, and 553 of the 1167 (47.4\%) who did not receive ECMO died. In the primary analysis, patients who received ECMO had lower mortality than those who did not ( $\mathrm{HR} 0.55 ; 95 \% \mathrm{Cl} 0.41-0.74)$. Results were similar in a secondary analysis limited to patients with $\mathrm{PaO}_{2} / \mathrm{FiO}_{2}<80(\mathrm{HR} 0.55 ; 95 \% \mathrm{Cl} 0.40-0.77)$.
\end{abstract}

Conclusion: In select patients with severe respiratory failure from COVID-19, ECMO may reduce mortality. Keywords: COVID-19, VV-ECMO, Extracorporeal membrane oxygenation, Severe respiratory failure, ARDS, Mortality

\footnotetext{
*Correspondence: sshaefi@bidmc.harvard.edu

${ }^{1}$ Department of Anesthesia, Critical Care and Pain Medicine, Beth Israel Deaconess Medical Center, Harvard Medical School, 1 Deaconess Road, Boston, MA 02215, USA

Full author information is available at the end of the article

Shahzad Shaefi, Samantha K. Brenner, and Shruti Gupta contributed equally.Ariel L. Mueller, Wei Wang, and David E. Leaf contributed equally.

The members of STOP-COVID Investigators are listed in the Acknowledgement section.
}

\section{重 Springer}




\section{Introduction}

Coronavirus disease 2019 (COVID-19) has caused nearly 1.5 million deaths globally as of November 29, 2020 [1]. Treatment of patients with severe hypoxemic respiratory failure from COVID-19 includes conventional therapies established for acute respiratory distress syndrome (ARDS), including invasive mechanical ventilation with lung protective strategies, prone positioning, neuromuscular blockade, and inhaled pulmonary vasodilators [2, $3]$. For patients who experience progressive respiratory failure despite these conventional therapies, venovenous extracorporeal membrane oxygenation (ECMO) may be considered to support gas exchange and minimize ventilator-induced lung injury $[4,5]$. ECMO has been used for decades in the treatment of severe ARDS of various etiologies. Recent clinical trials evaluated the efficacy and safety of ECMO in severe ARDS [6,7], with a survival benefit demonstrated in a meta-analysis [8].

Early reports from China, Europe, and the United States on the use of ECMO in patients with respiratory failure from COVID-19 have been limited by modest sample sizes and short follow-up [9-17]. More recent studies report larger numbers of patients who received ECMO, yet still suffer from lack of a comparative non-ECMO control group [18, 19]. Additional data are urgently needed to inform the potential efficacy and safety of ECMO in critically ill adults with severe respiratory failure from COVID-19.

To address this knowledge gap, we used data from a multicenter cohort study of critically ill patients with COVID-19 admitted to intensive care units (ICUs) across the United States to describe the clinical characteristics, physiologic parameters, complications, and outcomes of patients who initiated treatment with ECMO in the first 14 days of ICU admission. To estimate the effect of ECMO on survival in patients with COVID-19, we emulated a target trial in which patients with severe hypoxemic respiratory failure were categorized as having initiated or not initiated ECMO in the first 7 days of ICU admission.

\section{Methods}

\section{Study design and oversight}

We used data from the Study of the Treatment and Outcomes in Critically Ill Patients with COVID-19 (STOPCOVID), a multicenter cohort study that enrolled consecutive adults ( $\geq 18$ years old) with laboratory-confirmed COVID-19 admitted to participating ICUs at 68 geographically diverse hospitals across the United States [20]. The study was approved with a waiver of informed consent by the Institutional Review Board at each participating site.

\section{Take-home message}

In this multicenter cohort study of critically ill adults with COVID-19, 190 of 5122 patients (3.7\%) received ECMO, 127 (66.8\%) of whom survived to hospital discharge or 60 days. After accounting for differences between groups, patients with severe hypoxemia $\left(\mathrm{PaO}_{2} /\right.$ $\mathrm{FiO}_{2}<100$ ) who received ECMO in the first 7 days of ICU admission had lower in-hospital mortality than patients who did not (hazard ratio $0.55 ; 95 \% \mathrm{Cl} 0.41-0.74)$

\section{Study sites and patient population}

A total of 55 of the 68 participating hospitals in STOPCOVID were capable of treating patients with ECMO (Table E1). We included patients with COVID-19 who were admitted to an ICU at one of these 55 ECMO-capable participating hospitals between March 1 and July 1, 2020 (Fig. E1). Patients were considered to have received ECMO if they underwent cannulation for venovenous ECMO within 14 days following ICU admission (patients receiving venoarterial or veno-arterial-venous ECMO were excluded). We followed patients until hospital discharge, death, or September 1, 2020. All patients who remained hospitalized at the time of analysis had a minimum of 60 days of follow-up.

\section{Data collection}

Study personnel at each site collected data by manual chart review and used a standardized case report form to enter data using a secure, web-based platform [21]. Data included baseline information on demographics, coexisting conditions, symptoms, home medications, and vital signs on ICU admission, as well as daily data following ICU admission on laboratory and physiologic parameters (including the ratio of the partial pressure of arterial oxygen over the fraction of inspired oxygen $\left.\left[\mathrm{PaO}_{2} / \mathrm{FiO}_{2}\right]\right)$, medications, non-medication treatments, organ support, and outcome data on ICU and hospital length of stay and death. Among patients who received ECMO, additional data were collected on respiratory mechanics and ventilator parameters pre- and postECMO cannulation. Definitions of variables are provided in Table E2.

\section{Statistical analysis for descriptive cohort}

To describe baseline characteristics, treatment, and outcomes in patients who received ECMO within 14 days of ICU admission, continuous variables are expressed as median and interquartile range and categorical variables are presented as count and percentage. Among patients who received ECMO, differences between 60-day survivors and non-survivors were analyzed with a $t$ test or Mann-Whitney $U$ test for continuous data and with a Chi-square or Fisher's Exact test for categorical data, 
as appropriate. Patients who were discharged prior to 60 days were considered to be alive at 60 days.

\section{Eligibility criteria for the emulated trial}

To estimate the effect of ECMO on survival, we emulated a target trial comparing patients who initiated ECMO in the first 7 days of ICU admission to those who did not. Seven days was chosen as the time period for treatment assignment to provide greater homogeneity between patients, to allow for more follow-up time, and to be consistent with major trial exclusion criteria and consensus guidelines $[2,6,7,22]$. To emulate the eligibility criteria of a clinical trial of ECMO in patients with severe ARDS [23], we included patients with a $\mathrm{PaO}_{2} / \mathrm{FiO}_{2}$ ratio $<100 \mathrm{mmHg}$ while receiving invasive mechanical ventilation, and we excluded patients if they had any of the following characteristics: over 70 years old; malignancy treated in the prior year; treatment with venoarterial ECMO; or admission to an ICU at a hospital incapable of providing ECMO. $\mathrm{PaO}_{2} / \mathrm{FiO}_{2}$ ratio was assessed as the lowest $\mathrm{PaO}_{2}$ value (with the corresponding $\mathrm{FiO}_{2}$ value) on the day of ECMO initiation/non-initiation or the day prior.

\section{Target trial emulation}

The primary analysis compares the survival among ECMO initiators versus ECMO non-initiators. On day 1 of ICU admission, patients were categorized in the ECMO group if they received ECMO and were categorized in the non-ECMO group if they did not receive ECMO. We repeated this procedure on days 2 through 7 for eligible patients who had not previously received ECMO. This approach eliminates the immortal time bias that would result from comparing patients initiating ECMO at a later time point (e.g., ICU day 5) to patients who did not receive ECMO at an earlier time point (e.g., ICU day 1) [24]. Patients were followed from the date of ECMO initiation or non-initiation until death, hospital discharge, or the end of follow-up, whichever occurred first. Hazard ratios (HRs) and 95\% confidence intervals (CIs) were estimated using a Cox model. The final estimates of the effect of ECMO on survival were obtained by pooling the data from the emulation of the nested target trials on days 1 through seven of ICU admission.

\section{Multivariable adjustment for confounding}

We adjusted for confounding using a multivariable Cox model. The following covariates were prespecified based on clinical judgment and prior knowledge [20], as they were felt to potentially be associated with both ECMO receipt and with survival: age (18-49; 50-59; 60-70); sex; race (White; non-White); body mass index $(<40 ; \geq 40$; unknown); hypertension; diabetes mellitus; coronary artery disease; congestive heart failure; chronic obstructive pulmonary disease (COPD); $\mathrm{PaO}_{2} / \mathrm{FiO}_{2}$ ratio $(<80$; 80-99 $\mathrm{mmHg}$ ); shock (defined as receipt of at least one vasopressor); suspected or confirmed secondary infection; the renal, liver, and coagulation components of the Sequential Organ Failure Assessment score [25, 26]; and receipt of rescue therapies for hypoxemia (prone position ventilation, neuromuscular blockade, and inhaled vasodilators, each assessed separately). Acute severity of illness characteristics were assessed on the day of treatment assignment. Additional details are provided in the Supplementary Methods. We used a robust (sandwich) variance estimator to account for potential replications of patients induced by our nested target trial approach, which results in conservative (wider) 95\% CIs. In addition to the time-to-death analyses describe above, we also estimated the difference in the risk of 60-day mortality in ECMO-treated versus ECMO non-treated patients using the marginal probabilities from a logistic regression model that included the covariates listed above.

\section{Sensitivity analyses}

We also conducted a series of sensitivity analyses. First, we treated hospital discharge as a competing risk rather than a censoring event. Second, as an alternative approach to the primary analysis to eliminate immortal time bias, we matched each patient who initiated ECMO on day 1 with two randomly selected eligible control patients $\left(\mathrm{PaO}_{2} / \mathrm{FiO}_{2}\right.$ ratio $<100 \mathrm{mmHg}$ while receiving invasive mechanical ventilation) who did not initiate ECMO. We then repeated the process on days 2 through 7, with ECMO non-treated patients only being included once. Third, we limited our analysis to a more homogeneous group of patients with the following characteristics: $<65$ years old; absence of coronary artery disease, congestive heart failure, and COPD; mechanically ventilated and with a $\mathrm{PaO}_{2} /$ $\mathrm{FiO}_{2}$ ratio $<80 \mathrm{mmHg}$; and receipt of at least one rescue therapy for hypoxemia (prone position ventilation, neuromuscular blockade, or inhaled vasodilators) prior to ECMO initiation or non-initiation. For each of the above analyses, we adjusted for confounding by indication using a multivariable Cox model, as described above.

We performed two additional analyses similar to the primary analysis, but using alternative $\mathrm{PaO}_{2} / \mathrm{FiO}_{2}$ thresholds ( $<80$ and $<150 \mathrm{mmHg}$ ) to define eligibility. Finally, to assess the potential for effect modification according to day of treatment assignment, we tested the significance of an interaction term (treatment assignment $\times$ day of treatment [defined as day $1-3$ versus day 4-7]) introduced into the model. Analyses were performed using SAS software version 9.4 (SAS Institute). 


\section{Data completeness}

Rates of missing data overall are shown in Table E3. With the exception of body mass index, data were complete for all covariates included in the multivariable models. Missing data for body mass index (8.5\% of ECMO recipients and $3.3 \%$ of ECMO non-recipients) were not imputed. Rather, a separate missing category was used.

\section{Results}

\section{Baseline characteristics}

A total of 5122 critically ill patients with COVID-19 were admitted to ICUs during the study period. A total of 190 of the 5122 patients $(3.7 \%)$ received ECMO during the 14 days following ICU admission at 35 of the 55 ECMOcapable sites (Figs. 1 and E1). The median age of patients who received ECMO was 49 years (IQR 41-58) and 137 patients $(72.1 \%)$ were male (Tables 1 , E3). No patients who received venovenous ECMO were converted to venoarterial ECMO.

\section{Characteristics prior to ECMO}

Patients were cannulated at a median of 3 days (IQR 1-6) following ICU admission, and $83 \%$ of patients who received ECMO were cannulated in the first 7 days of ICU admission (Figure E2). Among the 188 patients with a $\mathrm{PaO}_{2} / \mathrm{FiO}_{2}$ ratio recorded in the $24 \mathrm{~h}$ prior to ECMO cannulation, $118(62.8 \%)$ had a $\mathrm{PaO}_{2} / \mathrm{FiO}_{2}$ ratio less than $80 \mathrm{mmHg}$, and $157(83.5 \%)$ had a $\mathrm{PaO}_{2} / \mathrm{FiO}_{2}$ ratio less than $100 \mathrm{mmHg}$ (Figure E3). $\mathrm{PaO}_{2} / \mathrm{FiO}_{2}$ ratio, positive end expiratory pressure, and receipt of therapies for hypoxemia were similar between 60-day survivors and non-survivors (Table 1). Survivors had a lower incidence of shock and a higher Respiratory ECMO Survival Prediction (RESP) score [27] in the $24 \mathrm{~h}$ prior to ECMO cannulation compared to non-survivors (Table 1).

\section{Complications after ECMO cannulation}

The most common complications after ECMO cannulation were bacterial pneumonia (34.7\%), bleeding (27.9\%), thrombotic events (22.6\%), and acute kidney injury requiring renal replacement therapy (21.8\%). Eight patients $(4.2 \%)$ had intracranial hemorrhage and three patients (1.6\%) had an ischemic stroke. Additional outcomes are shown in Table 2. Respiratory and laboratory parameters $24 \mathrm{~h}$ post-ECMO cannulation are shown in Table E4.

\section{Mortality and length of stay after ECMO cannulation}

Among the 190 patients who received ECMO, 63 (33.2\%) died, 94 (49.5\%) were discharged alive, and 33 (17.4\%) were still hospitalized at day 60 (Table 2). Among the survivors, the median ICU and hospital length of stay was 34 days (IQR 23-48) and 46 days (IQR 34-61), respectively (Table 2). When followed until the last date of follow-up, 67 patients (35.3\%) had died, $114(60 \%)$ were discharged alive, and only $9(4.7 \%)$ were still hospitalized. Of those who were discharged alive, 57 (50.4\%) were discharged home, $53(46.5 \%)$ were discharged to a rehabilitation facility, $3(2.7 \%)$ were transferred to another hospital, and 1 (0.9\%) was missing data on discharge location (Table E5). Of the 53 patients discharged to a rehabilitation facility, only $18(34 \%)$ went to a longterm acute care facility capable of providing invasive mechanical ventilation.

\section{Early vs. late cannulation}

Characteristics and outcomes of patients cannulated in the first compared to the second week following ICU admission are shown in Table E6.

\section{Target trial emulation}

Among 5122 patients examined, a total of 2068 were excluded from the target trial emulation (Fig. 1). Of the remaining 3054 patients, 1297 were eligible for inclusion in the target trial on at least 1 of the 7 days following ICU admission, 130 (10\%) of whom received ECMO and 1167 (90\%) of whom did not. The characteristics of ECMOtreated and non-treated patients are shown in Table 3. Patients treated with ECMO were younger, more likely to be male, and less likely to have chronic cardiovascular and respiratory disease compared to patients not treated with ECMO, but were more likely to have shock and a lower $\mathrm{PaO}_{2} / \mathrm{FiO}_{2}$ ratio (Table 3). Patients treated with ECMO were also more likely to have received rescue therapies for hypoxemia compared to those not treated with ECMO (Table 3).

Among the 1297 patients included in the target trial, during a median follow-up of 38 days (IQR 25-55), a total of 598 patients (46.1\%) died, including 45 of the 130 (34.6\%) who received ECMO and 553 of the 1167 (47.4\%) who did not (unadjusted HR 0.52; 95\% CI 0.4-0.69). Figure 2a shows the unadjusted survival curves (log-rank $p<0.001)$. In the primary analysis, patients who received ECMO had a lower risk of death compared to those who did not (adjusted HR 0.55; 95\% CI 0.41-0.74). Results of the full multivariable model are shown in Table E7. The estimated 60-day mortality was $35.3 \%$ (95\% CI $27.2-$ $43.5 \%)$ in the ECMO-treated patients and $47.9 \%$ (95\% CI $44.9-50.8 \%$ ) in the ECMO non-treated patients (risk difference 12.5\%; 95\% CI 4-21\%). Interpretations were unchanged across all three sensitivity analyses, as well as analyses using alternative $\mathrm{PaO}_{2} / \mathrm{FiO}_{2}$ thresholds to define eligibility (Fig. 2b; Tables E8-E11). No interaction was observed between treatment assignment and the day of treatment initiation ( $p$ value for interaction 0.15 ). 


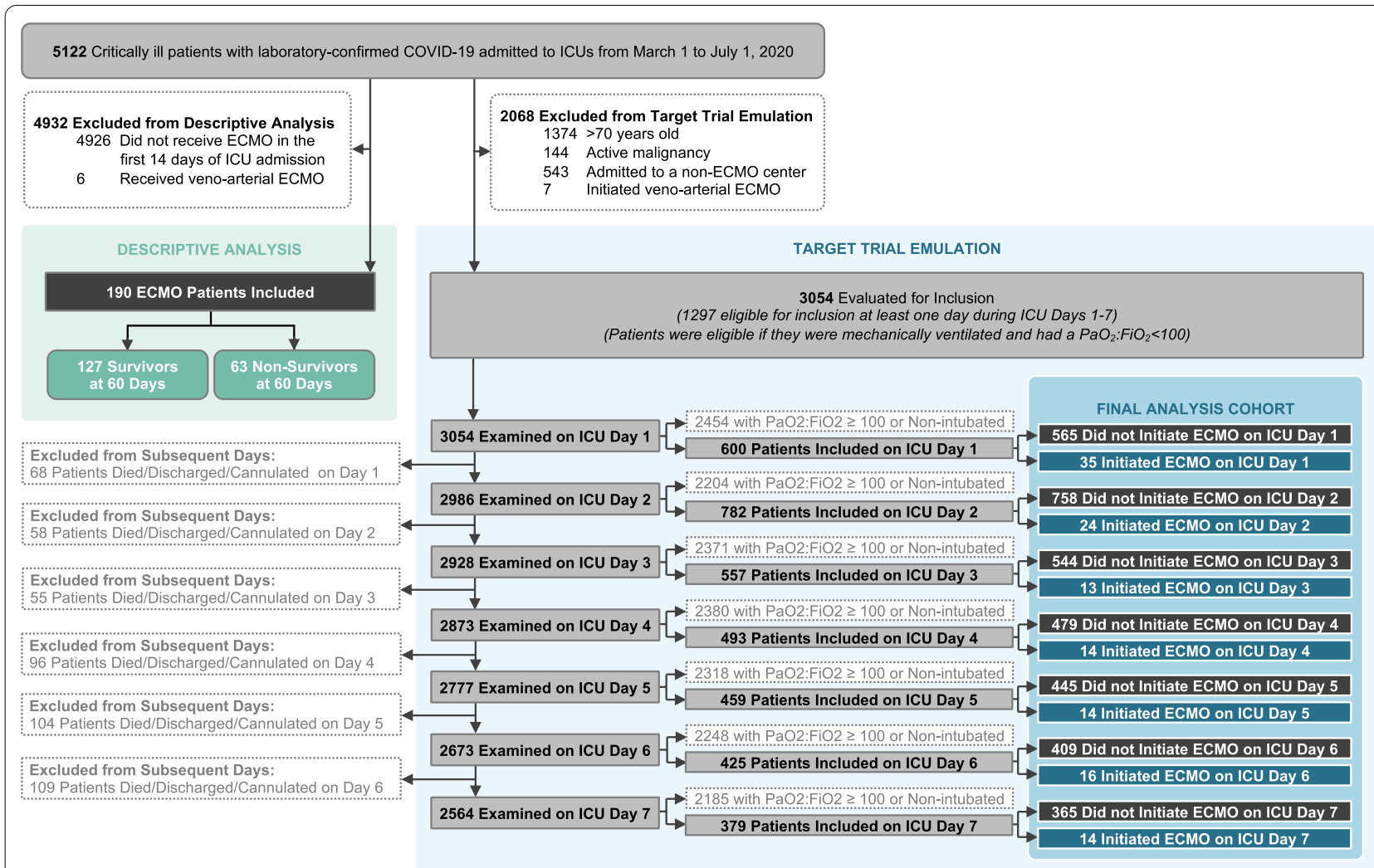

Fig. 1 Study cohort. Two populations of patients are shown: the descriptive analysis, which includes all patients who initiated ECMO in the first 14 days following ICU admission, and the target trial emulation, which includes patients who did or did not initiate ECMO in the first 7 days following ICU admission. For the target trial emulation, patients who initiated ECMO appeared in the pooled dataset up to and including the day that ECMO was initiated. For example, a patient who initiated ECMO on ICU day one did not have a corresponding observation on ICU days two through seven. A patient who initiated ECMO on ICU day three, meanwhile, appeared as both an ECMO non-initiator on days one and two and as an ECMO initiator on day three. ECMO extracorporeal membrane oxygenation, ICU intensive care unit, $\mathrm{PaO}_{2} / \mathrm{FiO}_{2}$ partial pressure of arterial oxygen over the fraction of inspired oxygen

\section{Discussion}

This multicenter cohort study of 190 critically ill adults with COVID-19 who received ECMO at 35 sites across the United States found that nearly $70 \%$ of patients survived to hospital discharge or 60 days following ICU admission. In a target trial emulation, severely hypoxemic patients who received ECMO in the first 7 days of ICU admission had a considerably lower risk of death compared to those who did not.

The current study presents data from a large, geographically diverse cohort from the United States. ECMO was used in $3 \%$ of critically ill adults with COVID-19 in our study; in a recent multicenter European cohort study, 8\% of critically ill patients with COVID-19 received ECMO [28]. The 60-day mortality rate of $33 \%$ that we observed for patients with COVID-19 treated with ECMO is similar to short-term mortality rates observed in ECMOtreated patients during prior pandemics, including mortality rates ranging from 28 to $37 \%$ among patients with H1N1 influenza [29, 30]. Our observed 60-day mortality rate is also similar to the 60-day mortality rate of $36 \%$ reported by a single-center study of 83 ECMOtreated patients with COVID-19 in France, and to the 90-day mortality rate of $37 \%$ reported in a large multinational ELSO study of over 1000 ECMO patients $[18,19]$.

The median age in our ECMO cohort was 49 years, and no patients over 70 were treated with ECMO. Patient selection guidelines for use of ECMO in COVID-19 are limited, and experts have suggested adhering to previously established protocols [2]. Over $70 \%$ of ECMO patients in our study underwent prone positioning prior to receiving ECMO, perhaps reflecting that the pandemic has spurred adoption of therapies that have been shown to have benefit but have previously been underutilized. The median pre-cannulation $\mathrm{PaO}_{2} / \mathrm{FiO}_{2}$ ratio in patients from our cohort was $72 \mathrm{mmHg}$, with over $80 \%$ of patients having a $\mathrm{PaO}_{2} / \mathrm{FiO}_{2}$ ratio below $100 \mathrm{mmHg}$, indicating severe hypoxemia, albeit not as severe as patients in the 
Table 1 Characteristics of patients who received ECMO

\begin{tabular}{|c|c|c|c|c|}
\hline Characteristic & $\begin{array}{l}\text { All ECMO patients } \\
(N=190)\end{array}$ & $\begin{array}{l}\text { ECMO 60-day sur- } \\
\text { vivors }(N=127)\end{array}$ & $\begin{array}{l}\text { ECMO 60-day non- } \\
\text { survivors }(N=63)\end{array}$ & $p$ value \\
\hline \multicolumn{5}{|l|}{ Baseline demographics } \\
\hline Age (year)—median (IQR) & $49(41-58)$ & $47(38-54)$ & $53(46$ to 60$)$ & 0.002 \\
\hline 18-39 & $45(23.7)$ & 35 (27.6) & $10(15.9)$ & 0.01 \\
\hline $40-49$ & $56(29.5)$ & $41(32.3)$ & $15(23.8)$ & \\
\hline $50-59$ & $54(28.4)$ & $35(27.6)$ & $19(30.2)$ & \\
\hline $60-70$ & $35(18.4)$ & $16(12.6)$ & $19(30.2)$ & \\
\hline Male sex-no. (\%) & $137(72.1)$ & $86(67.7)$ & $51(81)$ & 0.06 \\
\hline Body mass index $\left(\mathrm{kg} / \mathrm{m}^{2}\right)$ —median (IQR) & $32.7(29.1-38)$ & $33.2(29.5-38.3)$ & 31.3 (29 to 37.5$)$ & 0.32 \\
\hline Healthcare worker—no. (\%) & $7(3.7)$ & $5(3.9)$ & $2(3.2)$ & 0.89 \\
\hline \multicolumn{5}{|l|}{ Coexisting conditions-no. (\%) } \\
\hline Presence of any chronic condition & $119(62.6)$ & $77(60.6)$ & $42(66.7)$ & 0.42 \\
\hline Presence of multiple chronic conditions & $60(31.6)$ & $34(26.8)$ & $26(41.3)$ & 0.04 \\
\hline Chronic lung disease & $13(6.8)$ & $6(4.7)$ & $7(11.1)$ & 0.13 \\
\hline Coronary artery disease & $7(3.7)$ & $4(3.2)$ & $3(4.8)$ & 0.69 \\
\hline Chronic liver disease & $4(2.1)$ & $1(0.8)$ & $3(4.8)$ & 0.11 \\
\hline End-stage renal disease & $2(1.1)$ & $1(0.8)$ & $1(1.6)$ & 0.61 \\
\hline Active malignancy & $3(1.6)$ & $1(0.8)$ & $2(3.2)$ & 0.26 \\
\hline Pregnancy or postpartum & $5(2.6)$ & $4(3.2)$ & $1(1.6)$ & 0.53 \\
\hline \multicolumn{5}{|l|}{ Characteristics at ICU admission } \\
\hline \multicolumn{5}{|l|}{ Severity of illness indicators } \\
\hline Invasive mechanical ventilation—no. (\%) & $149(78.4)$ & 7.5 & $50(79.4)$ & 0.82 \\
\hline PEEP, $\mathrm{cmH}_{2} \mathrm{O}$-median (IQR) & $15(12-18)$ & $15(12-18)$ & $15(13$ to 16$)$ & 0.68 \\
\hline $\mathrm{PaO}_{2} / \mathrm{FiO}_{2}$ ratio ${ }^{\mathrm{a}}$, mmHg-median (IQR) & $85(66-120)$ & $82(66-111)$ & 87 (65 to 126) & 0.86 \\
\hline Acute kidney injury requiring RRT—no. (\%) & $11(5.9)$ & $8(6.4)$ & $3(4.8)$ & 0.68 \\
\hline Shock—no. (\%) & $108(56.8)$ & $68(53.5)$ & $40(63.5)$ & 0.19 \\
\hline \multicolumn{5}{|l|}{ ICU therapies prior to ECMO cannulation } \\
\hline \multicolumn{5}{|l|}{ Rescue therapies for hypoxemia-no. (\%) } \\
\hline Prone positioning & $135(71.1)$ & $87(68.5)$ & $48(76.2)$ & 0.27 \\
\hline Neuromuscular blockade & $149(78.4)$ & $96(75.6)$ & $53(84.1)$ & 0.18 \\
\hline Inhaled nitric oxide & $30(15.8)$ & $23(18.1)$ & $7(11.1)$ & 0.21 \\
\hline Inhaled epoprostenol & $36(19)$ & $24(18.9)$ & $12(19.1)$ & 0.98 \\
\hline Therapeutic anticoagulation-no. (\%) & $136(71.6)$ & $88(69.3)$ & $48(76.2)$ & 0.32 \\
\hline \multicolumn{5}{|c|}{$\begin{array}{l}\text { Acute organ injury and secondary infection within } 24 h \\
\text { prior to ECMO cannulation }\end{array}$} \\
\hline Acute kidney injury requiring RRT—no. (\%) & $33(17.6)$ & $18(14.3)$ & $15(24.2)$ & 0.09 \\
\hline Shock-no. (\%) & $157(82.6)$ & $100(78.7)$ & $57(90.5)$ & 0.04 \\
\hline Acute liver injury—no. (\%) & $4(2.1)$ & $0(0)$ & $4(6.4)$ & 0.01 \\
\hline Secondary infection—no. (\%) & $11(5.8)$ & $5(3.9)$ & $6(9.5)$ & 0.18 \\
\hline \multicolumn{5}{|c|}{ Characteristics within 24 h prior to ECMO cannulation ${ }^{b}$} \\
\hline RESP score-median (IQR) & $3(1-5)$ & $4(2-5)$ & $2(-1$ to 4$)$ & $<0.001$ \\
\hline $\mathrm{PaO}_{2} / \mathrm{FiO}_{2}$ ratio ${ }^{\mathrm{a}}, \mathrm{mmHg}$-median (IQR) & $72(61-90)$ & $74(63-93)$ & 69 (58 to 79$)$ & 0.02 \\
\hline$<80$ & $118(62.8)$ & $72(57.6)$ & $46(73)$ & 0.14 \\
\hline $80-99$ & $39(20.7)$ & $28(22.4)$ & $11(17.5)$ & \\
\hline $100-149$ & $28(14.9)$ & $23(18.4)$ & $5(7.9)$ & \\
\hline $150-200$ & $3(1.6)$ & $2(1.6)$ & $1(1.6)$ & \\
\hline PEEP, $\mathrm{cmH}_{2} \mathrm{O}$-median (IQR) & $15(14-18)$ & $16(14-18)$ & $15(14$ to 18$)$ & 0.66 \\
\hline $\mathrm{FiO}_{2}$-median (IQR) & $100(80-100)$ & $100(80-100)$ & 100 (80 to 100$)$ & 0.82 \\
\hline $\mathrm{PaCO}_{2}, \mathrm{mmHg}$-median (IQR) & $55(46-66)$ & $55(47-65)$ & 55 (45 to 68$)$ & 0.73 \\
\hline Tidal volume, ml/kg IBW_median (IQR) & $6(5.3-7.1)$ & $6(5.3-7.1)$ & $6.2(5.2$ to 7.1$)$ & 0.64 \\
\hline
\end{tabular}


Table 1 (continued)

\begin{tabular}{|c|c|c|c|c|}
\hline Characteristic & $\begin{array}{l}\text { All ECMO patients } \\
(N=190)\end{array}$ & $\begin{array}{l}\text { ECMO 60-day sur- } \\
\text { vivors }(N=127)\end{array}$ & $\begin{array}{l}\text { ECMO 60-day non- } \\
\text { survivors }(N=63)\end{array}$ & $p$ value \\
\hline Respiratory rate, $\min ^{-1}$ —median (IQR) & $27(22-30)$ & $26(21-30)$ & 28 (22 to 32 ) & 0.26 \\
\hline Plateau pressure, $\mathrm{CmH}_{2} \mathrm{O}$-median (IQR) & $30(28-35)$ & $30(28-35)$ & 31 (28 to 34) & 0.73 \\
\hline Driving pressure, $\mathrm{CmH}_{2} \mathrm{O}$-median (IQR) & $15(11-18)$ & $15(12-18)$ & 15 (11 to 17$)$ & 0.99 \\
\hline Compliance, $\mathrm{cmH}_{2} \mathrm{O}^{-1}$-median (IQR) & $28(21-36)$ & $27(19-38)$ & 30 (22 to 36$)$ & 0.41 \\
\hline \multicolumn{5}{|c|}{$\begin{array}{l}\text { Laboratory values within } 24 \text { h prior to ECMO cannula- } \\
\text { tion }^{b}\end{array}$} \\
\hline White cell count, per $\mathrm{mm}^{3}$ & $13.5(9.2-18.8)$ & $12.9(9-16.7)$ & 14.5 (9.6 to 21.9) & 0.15 \\
\hline Lymphocyte count, per $\mathrm{mm}^{3}$ & $5(3-8)$ & $6(3-8)$ & $4(3$ to 7$)$ & 0.29 \\
\hline Hemoglobin, g/dl & $10.8(9.5-12)$ & $11.1(9.9-12.4)$ & 10.2 (9.0 to 11.5$)$ & 0.01 \\
\hline Platelet count, per mm³ & $239(172-302)$ & 247 (191-313) & 188 (133 to 274) & 0.001 \\
\hline Albumin, g/dl & $2.4(2.1-2.8)$ & $2.5(2.2-3)$ & 2.3 (2.0 to 2.6 ) & 0.01 \\
\hline Arterial pH—median (IQR) & $7.30(7.23-7.36)$ & $7.31(7.26-7.36)$ & $7.29(7.21$ to 7.36$)$ & 0.08 \\
\hline Lactate, mmol/l & $1.9(1.4-2.9)$ & $1.9(1.5-2.9)$ & $2.2(1.4$ to 3.1$)$ & 0.20 \\
\hline D-dimer, ng/ml & $3483(1758-6860)$ & $3502(1758-7429)$ & 3340 (1780 to 5744) & 0.59 \\
\hline \multicolumn{5}{|l|}{ Timing characteristics-median (IQR) } \\
\hline Days from symptom onset to cannulation & $13(10-17)$ & $12(10-16)$ & 13 (9 to 18$)$ & 0.41 \\
\hline Days from hospital admission to cannulation & $6(4-9)$ & $5(3-7)$ & $6(4$ to 11$)$ & 0.01 \\
\hline Days from ICU admission to cannulation & $3(1-6)$ & $3(0-5)$ & $4(1$ to 6$)$ & 0.10 \\
\hline Days from mechanical ventilation to cannulation & $2(0-5)$ & $2(0-5)$ & $3(1$ to 6$)$ & 0.07 \\
\hline \multicolumn{5}{|l|}{ Hospital characteristics } \\
\hline Number of ICU beds-no. (\%) & & & & 0.10 \\
\hline$<50$ & $44(23.2)$ & 25 (19.7) & $19(30.2)$ & \\
\hline $50-99$ & & $38(20)$ & $23(18.1)$ & $15(23.8)$ \\
\hline$\geq 100$ & $108(56.8)$ & $79(62.2)$ & $29(46)$ & \\
\hline
\end{tabular}

Variable definitions are presented in Supplementary Table 2. Rates of missing data are reported in Table E3

$E C M O$ extracorporeal membrane oxygenation, $\mathrm{FiO}_{2}$ fraction of inspired oxygen, $I C U$ intensive care unit, IBW ideal body weight, $I Q R$ interquartile range, $P a O_{2}$ partial pressure of arterial oxygen, $\mathrm{PaCO}_{2}$ partial pressure of carbon dioxide, $P E E P$ positive end expiratory pressure, RESP respiratory extracorporeal membrane oxygenation survival prediction, $R R T$ renal replacement therapy

a $\mathrm{PaO}_{2} / \mathrm{FiO}_{2}$ refers to the ratio of the partial pressure of arterial oxygen $\left(\mathrm{PaO}_{2}\right)$ over the fraction of inspired oxygen $\left(\mathrm{FiO}_{2}\right)$ and was only assessed in patients receiving invasive mechanical ventilation. Values are recorded prior to ECMO initiation

b Includes values from the day prior to cannulation and the day of ECMO cannulation

EOLIA trial. In the EOLIA trial, criteria for ECMO initiation included a $\mathrm{PaO}_{2} / \mathrm{FiO}_{2}$ ratio $<50 \mathrm{mmHg}$ for more than $3 \mathrm{~h}$ or $\mathrm{PaO}_{2} / \mathrm{FiO}_{2}$ ratio $<80 \mathrm{mmHg}$ for more than $6 \mathrm{~h}$ [7]. Importantly, our sensitivity analyses performed in patients with $\mathrm{PaO}_{2} / \mathrm{FiO}_{2}<80$ and $<150 \mathrm{mmHg}$ demonstrated similar hazard ratios for survival as our primary analysis.

The high rates of complications we observed in patients with COVID-19 who received ECMO underscores the importance of patient selection. The most common complications were secondary infections, acute kidney injury, thrombotic events, and bleeding. Furthermore, half of the patients who survived to hospital discharge required some form of rehabilitation post-discharge, suggesting high morbidity in these patients. On the other hand, our finding that half of the patients who survived to hospital discharge were discharged home is reassuring that favorable outcomes can be achieved with ECMO with proper selection of patients.

We also sought to determine the effect of ECMO on survival. When data from randomized trials are not available, observational analyses may be used to guide 
Table 2 Outcomes of patients who received ECMO

\begin{tabular}{|c|c|c|c|c|}
\hline Outcome measure & $\begin{array}{l}\text { All ECMO patients } \\
(N=190)\end{array}$ & $\begin{array}{l}\text { ECMO 60-day survivors } \\
(N=127)\end{array}$ & $\begin{array}{l}\text { ECMO 60-day non-survi- } \\
\text { vors }(N=63)\end{array}$ & $p$ value \\
\hline \multicolumn{5}{|l|}{ 60-day outcomes-no. (\%) } \\
\hline Mortality status & & & & $<0.001$ \\
\hline Death & $63(33.2)$ & $0(0)$ & $63(100)$ & \\
\hline Survival to hospital discharge & $94(49.5)$ & $94(74)$ & $0(0)$ & \\
\hline Still hospitalized & $33(17.4)$ & $33(26)$ & $0(0)$ & \\
\hline \multicolumn{5}{|l|}{ Length of stay } \\
\hline ICU-median (IQR) & $31(20-43)$ & $34(23-48)$ & $25(14-25)$ & $<0.001$ \\
\hline Hospital—median (IQR) & $39(28-53)$ & $46(34-61)$ & $29(17-39)$ & $<0.001$ \\
\hline \multicolumn{5}{|l|}{ 28-day outcomes-no. (\%) } \\
\hline Decannulated from ECMO & $102(53.7)$ & $93(73.2)$ & $9(14.3)$ & $<0.001$ \\
\hline Liberation from mechanical ventilation & $59(31.1)$ & $57(44.9)$ & $2(3.2)$ & $<0.001$ \\
\hline Days of ECMO—median (IQR) & $16(10-23)$ & $16(10-24)$ & $16(9-22)$ & 0.28 \\
\hline Days of ventilation-median (IQR) & $26(17-28)$ & $26(19-28)$ & $23(14-28)$ & 0.03 \\
\hline \multicolumn{5}{|l|}{ 28-day complications-no. (\%) } \\
\hline Acute kidney injury requiring $\mathrm{RRT}^{\mathrm{a}}$ & $41(21.8)$ & $19(15.1)$ & $22(35.5)$ & 0.001 \\
\hline Pneumothorax requiring chest tube placement & $24(12.6)$ & $14(11)$ & $10(15.9)$ & 0.34 \\
\hline Thrombotic event & $43(22.6)$ & $32(25.2)$ & $11(17.5)$ & 0.23 \\
\hline Pulmonary embolism & $3(1.6)$ & $1(0.8)$ & $2(3.2)$ & 0.26 \\
\hline Deep vein thrombosis & $35(18.4)$ & $29(22.8)$ & $6(9.5)$ & 0.03 \\
\hline Ischemic stroke & $3(1.6)$ & $0(0)$ & $3(4.8)$ & 0.04 \\
\hline Other thrombotic event & $4(2.1)$ & $3(2.4)$ & $1(1.6)$ & 0.73 \\
\hline Bleeding complication & $53(27.9)$ & $23(18.1)$ & $30(47.6)$ & $<0.001$ \\
\hline Intracranial hemorrhage & $8(4.2)$ & $1(0.8)$ & $7(11.1)$ & 0.002 \\
\hline Other systemic bleeding events & $47(24.7)$ & $23(18.1)$ & $24(38.1)$ & 0.003 \\
\hline Both thrombotic and bleeding events & $14(7.4)$ & $7(5.5)$ & $7(11.1)$ & 0.24 \\
\hline Bacterial pneumonia & $66(34.7)$ & $41(32.3)$ & $25(39.7)$ & 0.31 \\
\hline Other culture-documented infections & $35(18.4)$ & $28(22.1)$ & $7(11.1)$ & 0.07 \\
\hline
\end{tabular}

Outcome definitions are defined in Supplementary Table 2

ECMO extracorporeal membrane oxygenation, ICU intensive care unit, IQR interquartile range, $R R T$ renal replacement therapy

a Values are only reported for patients without end-stage renal disease at baseline

practice by adopting a target trial emulation approach [31-34]. Accordingly, we conducted a target trial emulation in which severely hypoxemic patients were categorized according to receipt or no receipt of ECMO in the first 7 days of ICU admission. We used analytic approaches to adjust for confounding and prevent immortal time bias. We found that severely hypoxemic patients treated with ECMO had a considerably lower risk of death compared to patients not treated with ECMO, with similar results across multiple sensitivity and subgroup analyses. Since randomized controlled trials of ECMO use in COVID-19 are unlikely to be feasible in the foreseeable future due to logistical challenges and inevitable cross-over, target trial emulation may offer the best available evidence on which to base current practice. Nevertheless, the findings from our target trial emulation, which are based on observational data, should be interpreted cautiously since we cannot exclude the potential for residual confounding.

Our study has several strengths. We collected granular data (over 800 unique data elements per patient) from a large number of consecutive critically ill patients with laboratory-confirmed COVID-19, thereby minimizing selection or surveillance bias at each center. We included patients from 55 geographically diverse sites from across the United States, thereby increasing the generalizability of our findings, and we excluded patients from centers not capable of performing ECMO. All data were obtained by detailed chart review rather than reliance on administrative or billing codes, which have well-described limitations [31, 35]. Whereas some prior studies of ECMO in COVID-19 have had limited followup, we followed patients until hospital discharge, death, or a minimum of 60 days, which allowed us to ascertain 
Table 3 Characteristics of patients included in the target trial emulation of ECMO versus no ECMO

\begin{tabular}{|c|c|c|c|c|}
\hline & \multicolumn{2}{|l|}{ Unique patients } & \multicolumn{2}{|l|}{ Final cohort $^{\mathrm{a}}$} \\
\hline & $\overline{E C M O}(N=130)$ & No ECMO $(N=1167)$ & $\overline{E C M O}(N=130)$ & No ECMO $(N=3565)$ \\
\hline \multicolumn{5}{|l|}{ Demographic characteristics } \\
\hline \multicolumn{5}{|l|}{ Age (years) } \\
\hline Median (IQR) & $49(41-58)$ & $58(49-64)$ & $49(41-58)$ & $58(48-64)$ \\
\hline 18-49-no. (\%) & $66(50.8)$ & $308(26.4)$ & $66(50.8)$ & $1015(28.5)$ \\
\hline 50-59-no. (\%) & $41(31.5)$ & $350(30)$ & $41(31.5)$ & $1060(29.7)$ \\
\hline 60-70-no. (\%) & $23(17.7)$ & $509(43.6)$ & $23(17.7)$ & $1490(41.8)$ \\
\hline Male sex-no. (\%) & $95(73.1)$ & $757(64.9)$ & $95(73.1)$ & $2337(65.6)$ \\
\hline White race-no. (\%) & $51(39.2)$ & $402(34.4)$ & $51(39.2)$ & $1252(35.1)$ \\
\hline \multicolumn{5}{|l|}{ Body mass index $\left(\mathrm{kg} / \mathrm{m}^{2}\right)$} \\
\hline Median (IQR) & $32.5(29.5-37.9)$ & $32.5(28.1-39.1)$ & $32.5(29.5-37.9)$ & $32.8(28.4-39.5)$ \\
\hline$<40$-no. (\%) & $98(75.4)$ & $867(74.3)$ & $98(75.4)$ & $2618(73.4)$ \\
\hline$\geq 40$-no. $(\%)$ & $21(16.2)$ & $261(22.4)$ & $21(16.2)$ & $831(23.3)$ \\
\hline Unknown-no. (\%) & $11(8.5)$ & $39(3.3)$ & $11(8.5)$ & $116(3.3)$ \\
\hline \multicolumn{5}{|l|}{ Coexisting conditions } \\
\hline Hypertension & $62(47.7)$ & $682(58.4)$ & $62(47.7)$ & $2067(58)$ \\
\hline Diabetes mellitus & $38(29.2)$ & $516(44.2)$ & $38(29.2)$ & $1524(42.7)$ \\
\hline Coronary artery disease & $4(3.1)$ & $120(10.3)$ & $4(3.1)$ & $350(9.8)$ \\
\hline Congestive heart failure & $2(1.5)$ & $108(9.3)$ & $2(1.5)$ & $324(9.1)$ \\
\hline Chronic obstructive pulmonary disease & $4(3.1)$ & $86(7.4)$ & $4(3.1)$ & $264(7.4)$ \\
\hline \multicolumn{5}{|l|}{ Severity of illness ${ }^{b}$} \\
\hline $\mathrm{PaO}_{2} / \mathrm{FiO}_{2}, \mathrm{mmHg}$-median (IQR) & $80(65-99)$ & $90(70-128)$ & $69(60-80)$ & $78(66-89)$ \\
\hline PEEP_median (IQR) & $15(12-18)$ & $14(10-16)$ & $15(12-18)$ & $14(12-18)$ \\
\hline Shock ${ }^{c}-$ no. (\%) & $81(62.3)$ & $622(53.3)$ & $104(80)$ & $2352(66)$ \\
\hline Lactate, mmol/l-median (IQR) & $1.7(1.2-2.5)$ & $1.6(1.1-2.3)$ & $2.0(1.4-3.1)$ & $1.5(1.1-2.1)$ \\
\hline Arterial pH—median (IQR) & $7.35(7.29-7.45)$ & $7.36(7.28-7.42)$ & $7.33(7.28-7.39)$ & $7.34(7.27-7.39)$ \\
\hline Secondary infection-no. (\%) & $11(8.5)$ & $83(7.1)$ & $26(20)$ & $595(16.7)$ \\
\hline \multicolumn{5}{|l|}{ Renal SOFA score-no. (\%) ${ }^{d}$} \\
\hline $0(\mathrm{Cr}<1.2 \mathrm{mg} / \mathrm{dl})$ & $84(64.6)$ & $664(56.9)$ & $67(51.5)$ & $1595(44.7)$ \\
\hline $1(\mathrm{Cr} 1.2-1.9 \mathrm{mg} / \mathrm{dl})$ & $29(22.3)$ & $250(21.4)$ & $34(26.2)$ & $752(21.1)$ \\
\hline 2-4 (Cr > 2 mg/dl, UOP < $\left.500 \mathrm{ml}, \mathrm{RRT}^{\mathrm{e}}\right)$ & $17(13.1)$ & $253(21.7)$ & $29(22.3)$ & $1218(34.2)$ \\
\hline \multicolumn{5}{|l|}{ Liver SOFA score-no. (\%) ${ }^{d}$} \\
\hline 0 (Bilirubin < 1.2 mg/dl) & $114(87.7)$ & $1058(90.7)$ & $109(83.8)$ & $3088(86.6)$ \\
\hline 1 (Bilirubin $1.2-1.9$ mg/dl) & $11(8.5)$ & $80(6.9)$ & $13(10)$ & $292(8.2)$ \\
\hline 2-4 (Bilirubin $\geq 2$ mg/dl) & $5(3.8)$ & $29(2.5)$ & $8(6.2)$ & $185(5.2)$ \\
\hline \multicolumn{5}{|l|}{ Coagulation SOFA score-no. $(\%)^{d}$} \\
\hline 0 (Platelet count $\geq 150 \mathrm{~K} / \mathrm{mm}^{3}$ ) & $109(83.8)$ & $995(85.3)$ & $108(83.1)$ & $3111(87.3)$ \\
\hline 1 (Platelet count $100-149 \mathrm{~K} / \mathrm{mm}^{3}$ ) & $15(11.5)$ & $135(11.6)$ & $17(13.1)$ & $335(9.4)$ \\
\hline 2-4 (Platelet count < $100 \mathrm{~K} / \mathrm{mm}^{3}$ ) & $6(4.6)$ & $37(3.2)$ & $5(3.8)$ & $119(3.3)$ \\
\hline \multicolumn{5}{|l|}{ Rescue therapies for hypoxemia-no. $(\%)^{f}$} \\
\hline Prone position ventilation & $56(43.1)$ & $249(21.3)$ & $92(70.8)$ & $1651(46.3)$ \\
\hline Neuromuscular blockade & $52(40)$ & $234(20.1)$ & $100(76.9)$ & $1678(47.1)$ \\
\hline Inhaled vasodilators & $23(17.7)$ & $49(4.2)$ & $47(36.2)$ & $479(13.4)$ \\
\hline
\end{tabular}

$\mathrm{PaO}_{2}$ partial pressure of arterial oxygen over the fraction of inspired oxygen, $P E E P$ positive end expiratory pressure, RRT renal replacement therapy, SOFA Sequential Organ Failure Assessment, UOP urine output

a The number of observations in the final cohort differs from the number of unique patients because more than one observation per patient was used, thereby creating a pseudo-cohort. This approach (described further in the supplemental methods) was used to eliminate the potential for immortal time bias

b Severity of illness data are shown on the day of ICU admission for the unique patients and on the day of ECMO initiation or non-initiation for the final cohort

c Shock is defined as the requirement for at least one vasopressor

d Categories 2, 3, and 4 of the renal, liver, and coagulation components of the SOFA score were binned due to low frequency of events

e Includes both acute RRT as well as end-stage renal disease requiring RRT

${ }^{f}$ Rescue therapies for hypoxemia were assessed on the day of ICU admission for the unique patients and up to and including the day of ECMO initiation or noninitiation for the final cohort 
a definitive outcome (dead or discharged) in $95 \%$ of the patients who received ECMO. Finally, the results of our target trial emulation were consistent across multiple sensitivity analyses that used alternative methodological approaches, along with alternative thresholds of hypoxemia to define eligibility.

We also acknowledge several limitations. First, as with all observational analyses, we cannot rule out the possibility of residual confounding. For example, we did not account for varying degrees of hospital strain, which could affect outcomes in critical care during dynamic surges in patient volumes. Second, we acknowledge that sites may have varied in the criteria they used to determine ECMO candidacy. For example, use of rescue therapies for hypoxemia (prone positioning, neuromuscular blockade, and inhaled vasodilators) prior to ECMO initiation, and use of therapeutic anticoagulation during ECMO, were based on institutional standards of care during the pandemic and reflect site variation in practice. Importantly, our sensitivity analysis limited to a more homogeneous group of patients, including those who received at least one rescue therapy prior to ECMO initiation or non-initiation, found similar findings as our primary analysis. Third, inclusion criteria for our target trial emulation included assessment of the lowest $\mathrm{PaO}_{2} / \mathrm{FiO}_{2}$ in the $24 \mathrm{~h}$ preceding ECMO cannulation, unlike the EOLIA trial, which used a set duration of time below a $\mathrm{PaO}_{2} /$ $\mathrm{FiO}_{2}$ threshold. Fourth, we did not collect longitudinal data on respiratory mechanics beyond $24 \mathrm{~h}$ or prone positioning during ECMO [36, 37], which could have been used to further assess lung rest, recovery, and recruitability. It should also be acknowledged that only modest reductions in tidal volumes and driving pressures were observed in the immediate post-ECMO period, somewhat in contrast with other studies demonstrating ultraprotective lung ventilation on ECMO $[18,38]$. We also did not collect data on lung compliance in patients who did not receive ECMO. Fifth, for our descriptive analyses patients discharged prior to 60 days were assumed to still be alive at day 60 , an assumption that may have overestimated the 60-day survival rate of ECMO recipients. However, we note that $97 \%$ of those discharged were either discharged home or to a rehabilitation facility, with only $3 \%$ having been transferred to another hospital.

Using data from a nationally representative and geographically diverse multicenter cohort study of critically ill adults with COVID-19 in the United States, we found that 190 patients were treated with ECMO. Among those treated with ECMO, two-thirds survived to hospital discharge or 60 days. Using target trial emulation, we found that selected patients with severe hypoxemic respiratory failure treated with ECMO in the first 7 days of ICU admission had a considerable reduction in mortality compared to those not treated with ECMO. Although clear indications for ECMO in COVID-19 patients are not explicitly provided in this cohort study, it is evident that a proportion of patients with severe COVID-19 respiratory failure may well benefit from ECMO. Further investigation is warranted to identify which COVID-19 patients may derive the greatest benefit from ECMO.

\footnotetext{
(See figure on next page.)

Fig. 2 The estimated effect of ECMO on mortality. a Shows the unadjusted survival curves for ECMO-treated versus ECMO non-treated patients. $\mathbf{b}$ Shows the hazard ratios for survival for ECMO-treated versus ECMO non-treated patients. The following covariates were included in the multivariable models: age; sex; race; body mass index; hypertension; diabetes mellitus; coronary artery disease; congestive heart failure; chronic obstructive pulmonary disease; shock; suspected or confirmed secondary infection; the renal, liver, and coagulation components of the Sequential Organ Failure Assessment score $[25,26]$; and receipt of rescue therapies for hypoxemia (prone position ventilation, neuromuscular blockade, and inhaled vasodilators, each assessed separately). Sensitivity analysis \#1 treated hospital discharge as a competing risk rather than as a censoring event. Sensitivity analysis \#2 matched each ECMO-treated patient on day 1 with two randomly selected eligible control patients $\left(\mathrm{PaO}_{2} / \mathrm{FiO}_{2}\right.$ ratio $<100 \mathrm{mmHg}$ while receiving invasive mechanical ventilation) who did not initiate $\mathrm{ECMO}$, and the process was then repeated on days 2 through 7 , with $\mathrm{ECMO}$ non-treated patients only being used once. Sensitivity analysis \#3 was limited to patients with the following characteristics: $<65$ years old; absence of coronary artery disease, congestive heart failure, and COPD; mechanically ventilated and with $\mathrm{PaO}_{2} / \mathrm{FiO}_{2}$ ratio $<80$ mmHg; and receipt of at least one rescue therapy for hypoxemia (prone position ventilation, neuromuscular blockade, or inhaled vasodilators) prior to ECMO initiation or noninitiation. ECMO extracorporeal membrane oxygenation, $\mathrm{PaO}_{2} / \mathrm{FiO}_{2}$ partial pressure of arterial oxygen over the fraction of inspired oxygen
} 
a

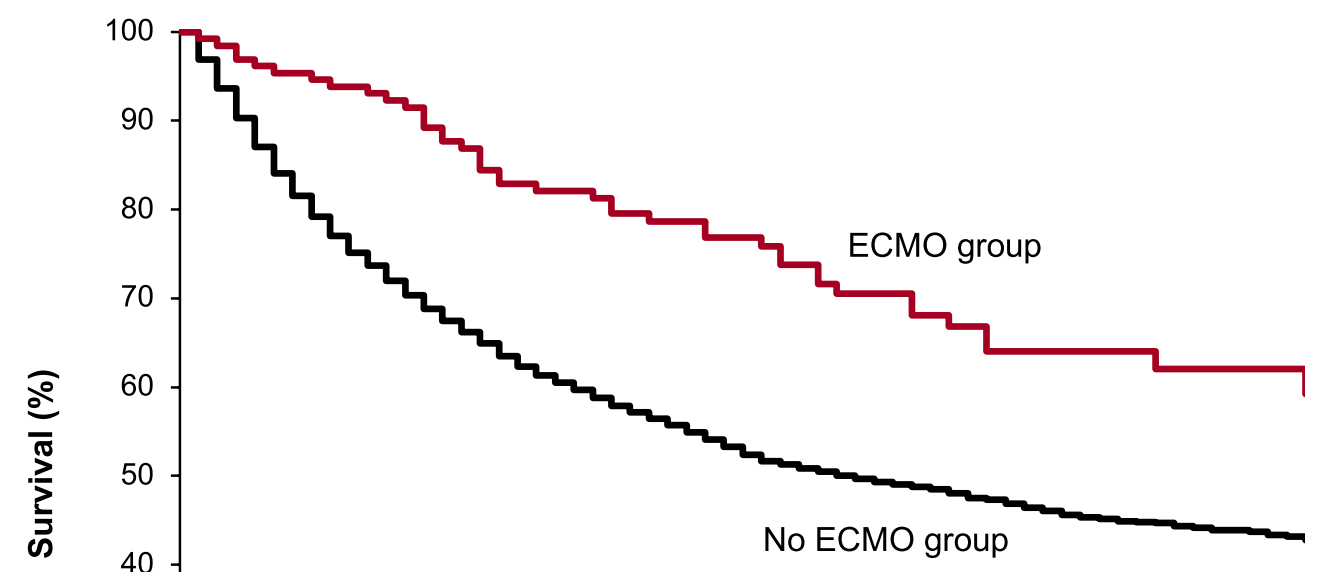

No. at risk

$\begin{array}{lccccccc} & \text { Day 0 } & \text { Day 10 } & \text { Day 20 } & \text { Day 30 } & \text { Day 40 } & \text { Day 50 } & \text { Day 60 } \\ \text { ECMO } & 130 & 122 & 101 & 79 & 54 & 38 & 22 \\ \text { No ECMO } & 3565 & 2618 & 1819 & 1171 & 773 & 477 & 298\end{array}$

b

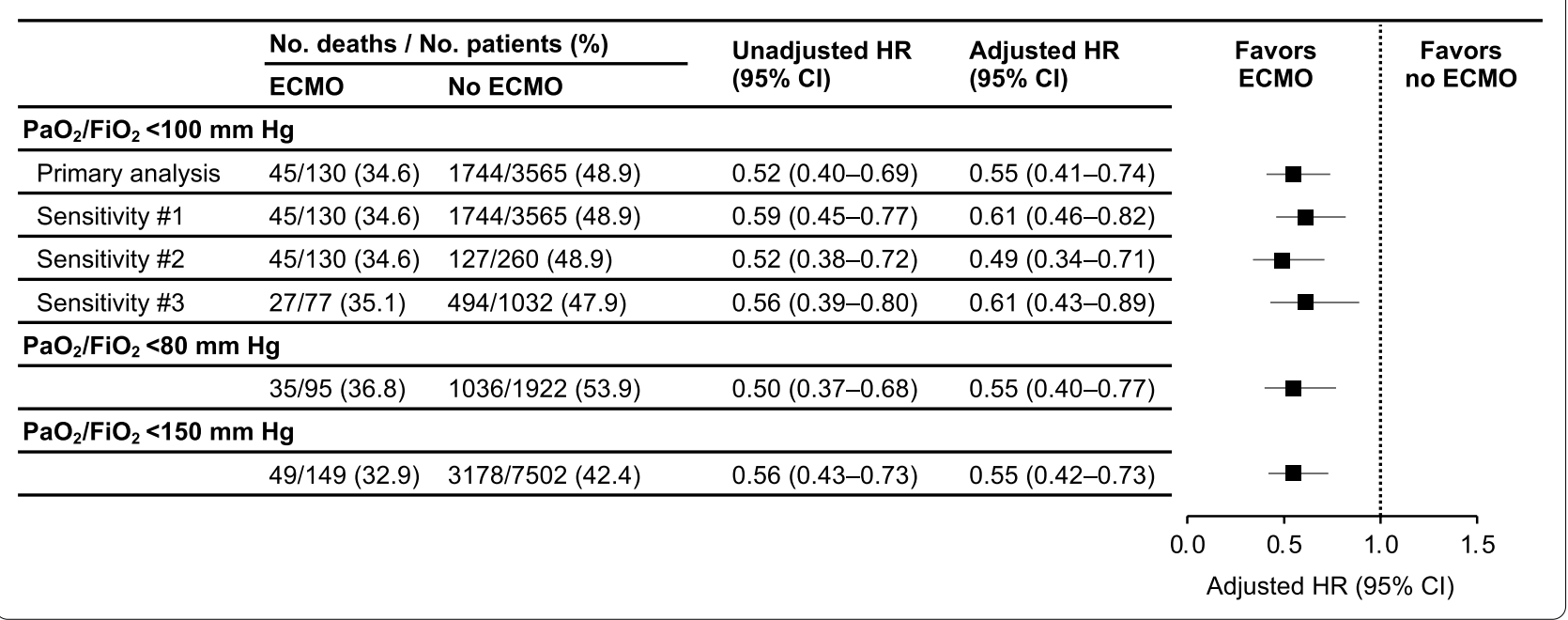




\section{Supplementary Information}

The online version contains supplementary material available at https://doi. org/10.1007/s00134-020-06331-9.

\section{Author details}

${ }^{1}$ Department of Anesthesia, Critical Care and Pain Medicine, Beth Israel Deaconess Medical Center, Harvard Medical School, 1 Deaconess Road, Boston, MA 02215, USA. ${ }^{2}$ Department of Internal Medicine, Hackensack Meridian School of Medicine at Seton Hall, Nutley, NJ, USA. ${ }^{3}$ Department of Internal Medicine, Heart and Vascular Hospital, Hackensack Meridian Health Hackensack University Medical Center, Hackensack, NJ, USA. ${ }^{4}$ Division of Renal Medicine, Brigham and Women's Hospital, Boston, MA, USA. ${ }^{5}$ Division of Nephrology, New York University Grossman School of Medicine, New York, NY, USA. ${ }^{6}$ Division of Pulmonary and Critical Care Medicine, Rush University Medical Center, Chicago, IL, USA. ${ }^{7}$ Department of Medicine, Rush University Medical Center, Chicago, IL, USA. ${ }^{8}$ Department of Surgery, Hackensack Meridian School of Medicine at Seton Hall, Nutley, NJ, USA. ${ }^{9}$ Division of Cardiac Surgery, Heart and Vascular Hospital, Hackensack Meridian Health Hackensack University Medical Center, Hackensack, NJ, USA. ${ }^{10}$ Division of Renal Diseases and Hypertension, University of Colorado Anschutz Medical Campus, Aurora, CO, USA. ${ }^{11}$ Division of Cardiology, Department of Medicine, University of Michigan, Ann Arbor, MI, USA. ${ }^{12}$ Division of Nephrology and Hypertension, Center for Translational Metabolism and Health, Institute for Public Health and Medicine, Northwestern University Feinberg School of Medicine, Chicago, IL, USA. ${ }^{13}$ Division of Pulmonary, Critical Care, and Sleep Medicine, Icahn School of Medicine at Mount Sinai, New York, NY, USA. ${ }^{14}$ Division of Nephrology, Department of Medicine, Albert Einstein College of Medicine/Montefiore Medical Center, The Bronx, NY, USA. ${ }^{15}$ Renal-Electrolyte and Hypertension Division, Perelman School of Medicine, University of Pennsylvania, Philadelphia, PA, USA. ${ }^{16}$ Division of Critical Care Medicine, Cooper University Health Care, Camden, NJ, USA. ${ }^{17}$ Department of Internal Medicine, Baylor University Medical Center, Baylor Research Institute, Dallas, TX, USA. ${ }^{18}$ Division of Pulmonary, Allergy, and Critical Care Medicine, University of Alabama at Birmingham, Birmingham, AL, USA. ${ }^{19}$ Division of Pulmonary and Critical Care Medicine, Department of Internal Medicine, University of Michigan, Ann Arbor, MI, USA. ${ }^{20}$ Division of Allergy, Pulmonary, and Critical Care Medicine, Vanderbilt University Medical Center, Nashville, TN, USA. ${ }^{21}$ Departments of Epidemiology and Biostatistics, Harvard T.H. Chan School of Public Health, Boston, MA, USA. ${ }^{22}$ Harvard-MIT Division of Health Sciences and Technology, Cambridge, MA, USA. ${ }^{23}$ Department of Anesthesia, Critical Care and Pain Medicine, Massachusetts General Hospital, Boston, MA, USA. ${ }^{24}$ Departments of Medicine and Neurology, Brigham and Women's Hospital, Boston, MA, USA.

\section{Acknowledgements}

The members of STOP-COVID investigators are: Baylor College of Medicine: Carl P. Walther*, Samaya J. Anumudu. Baylor University Medical Center: Justin Arunthamakun*, Kathleen F. Kopecky, Gregory P. Milligan, Peter A. McCullough, Thuy-Duyen Nguyen. Beth Israel Deaconess Medical Center: Shahzad Shaefi,* Brian P. O'Gara, Megan L. Krajewski, Sean M. Baskin, Sidharth Shankar, Juan D. Valencia, Ameeka Pannu, Margaret M. Hayes, E. Wilson Grandin. Boston Medical Center: Sushrut S. Waikar*, Zoe A. Kibbelaar. Cook County Health: Ambarish M. Athavale*, Peter Hart, Shristi Upadhyay, Ishaan Vohra, Ajiboye Oyintayo. Cooper University Health Care: Adam Green*, Jean-Sebastien Rachoin, Christa A. Schorr, Lisa Shea. Duke University Medical Center: Daniel L. Edmonston*, Christopher L. Mosher. Hackensack Meridian Health Mountainside Medical Center: Alexandre M. Shehata*, Zaza Cohen, Valerie Allusson, Gabriela Bambrick-Santoyo, Noor ul aain Bhatti, Bijal Mehta, Aquino Williams. Hackensack Meridian Health Hackensack University Medical Center: Samantha K. Brenner*, Patricia Walters, Ronaldo C. Go, Keith M. Rose. Harvard T.H. Chan School of Public Health: Miguel A. Hernán Harvard University: Rebecca Lisk. Icahn School of Medicine at Mount Sinai: Lili Chan*, Kusum S. Mathews*, Steven G. Coca, Deena R. Altman, Aparna Saha, Howard Soh, Huei Hsun Wen, Sonali Bose, Emily A. Leven, Jing G. Wang, Gohar Mosoyan, Girish N. Nadkarni, Pattharawin Pattharanitima, Emily J. Gallagher. Indiana University School of Medicine/Indiana University Health: Allon N. Friedman*, John Guirguis, Rajat Kapoor, Christopher Meshberger, Katherine J. Kelly. Johns Hopkins Hospital: Chirag R. Parikh*, Brian T. Garibaldi, Celia P. Corona-Villalobos, Yumeng Wen, Steven Menez, Rubab F. Malik, Carmen Elena Cervantes, Samir C. Gautam. Kings County Hospital Center: Mary C. Mallappallil*, Jie Ouyang, Sabu John, Ernie Yap, Yohannes Melaku, Ibrahim Mohamed, Siddhartha Bajracharya, Isha
Puri, Mariah Thaxton, Jyotsna Bhattacharya, John Wagner, Leon Boudourakis. Loma Linda University: H. Bryant Nguyen*, Afshin Ahoubim. Mayo Clinic, Arizona: Leslie F. Thomas*, Dheeraj Reddy Sirganagari. Mayo Clinic, Florida: Pramod K. Guru*. Mayo Clinic, Rochester: Kianoush Kashani*, Shahrzad Tehranian. Medical College of Wisconsin: Yan Zhou, ${ }^{*}$ Paul A. Bergl, Jesus Rodriguez, Jatan A. Shah, Mrigank S. Gupta. MedStar Georgetown University Hospital: Princy N. Kumar*, Deepa G. Lazarous, Seble G. Kassaye. Montefiore Medical Center/Albert Einstein College of Medicine: Michal L. Melamed* Tanya S. Johns. Ryan Mocerino, Kalyan Prudhvi, Denzel Zhu, Rebecca V. Levy, Yorg Azzi, Molly Fisher, Milagros Yunes, Kaltrina Sedaliu, Ladan Golestaneh, Maureen Brogan, Neelja Kumar, Michael Chang, Jyotsana Thakkar. New York-Presbyterian Queens Hospital: Ritesh Raichoudhury*, Akshay Athreya, Mohamed Farag. New York-Presbyterian/Weill Cornell Medical Center: Edward J. Schenck*, Soo Jung Cho, Maria Plataki, Sergio L. Alvarez-Mulett, Luis G. Gomez-Escobar, Di Pan, Stefi Lee, Jamuna Krishnan, William Whalen. New York University Langone Hospital: David Charytan*, Ashley Macina, Sobaata Chaudhry, Benjamin Wu, Frank Modersitzk. Northwestern Memorial Hospital: Northwestern University Feinberg School of Medicine-Anand Srivastava*, Alexander S. Leidner, Carlos Martinez, Jacqueline M. Kruser, Richard G. Wunderink, Alexander J. Hodakowski. Ochsner Medical Center: Juan Carlos Q. Velez*, Eboni G. Price-Haywood, Luis A. Matute-Trochez, Anna E. Hasty, Muner MB. Mohamed Oregon Health and Science University Hospital: Rupali S. Avasare*, David Zonies*. Partners Healthcare: Brigham and Women's Hospital, Brigham and Women's Faulkner. Hospital, Massachusetts General Hospital, and Newton Wellesley Hospital - David E. Leaf*, Shruti Gupta*, Meghan E. Sise, Erik T. Newman, Samah Abu Omar, Kapil K. Pokharel, Shreyak Sharma, Harkarandeep Singh, Simon Correa, Tanveer Shaukat, Omer Kamal, Wei Wang, Heather Yang, Jeffery O. Boateng, Meghan Lee, Ian A. Strohbehn, Jiahua Li, Ariel L. Mueller. ProMedica Health System: Roberta E. Redfern, ${ }^{*}$ Nicholas S. Cairl, Gabriel Naimy, Abeer Abu-Saif, Danyell Hall, Laura Bickley. Renown Health: Chris Rowan*, Farah Madhani-Lovely*. Rush University Medical Center: Vasil Peev*, Jochen Reiser, John J. Byun, Andrew Vissing, Esha M. Kapania, Zoe Post, Nilam P. Patel, Joy-Marie Hermes. Rutgers/New Jersey Medical School: Anne K. Sutherland*, Amee Patrawalla, Diana G. Finkel, Barbara A. Danek, Sowminya Arikapudi, Jeffrey M. Paer, Peter Cangialosi, Mark Liotta. Rutgers/Robert Wood Johnson Medical School: Jared Radbel*, Sonika Puri, Jag Sunderram, Matthew T. Scharf, Ayesha Ahmed, Ilya Berim, Jayanth S. Vatson. Stanford Healthcare: Stanford University School of Medicine - Shuchi Anand*, Joseph E. Levitt, Pablo Garcia. Temple University Hospital: Suzanne M. Boyle*, Rui Song, Ali Arif. Thomas Jefferson Health: Jingjing Zhang*, Sang Hoon Woo, Xiaoying Deng, Goni Katz-Greenberg, Katharine Senter. Tulane Medical Center: Moh'd A. Sharshir*, Vadym V. Rusnak. United Health Services Hospitals: Muhammad Imran Ali, Terri Peters, Kathy Hughes. University of Colorado Anschutz Medical Campus: Anip Bansal*, Amber S. Podoll, Michel Chonchol, Sunita Sharma, Ellen L. Burnham University Hospitals Cleveland Medical Center: Arash Rashidi*, Rana Hejal. University of Alabama-Birmingham Hospital: Eric Judd*, Laura Latta, Ashita Tolwani. University of California-Davis Medical Center:Timothy E. Albertson*, Jason Y. Adams. University of California-Los Angeles Medical Center: Ronald Reagan-UCLA Medical Center. Steven Y. Chang*, Rebecca M. Beutler; Santa Monica-UCLA Medical Center - Carl E. Schulze. University of California-San Diego Medical Center: Etienne Macedo*, Harin Rhee. University of California-San Francisco Medical Center: Kathleen D. Liu*, Vasantha K. Jotwani. University of Chicago Medical Center: Jay L. Koyner*, Alissa Kunczt. University of Florida Health-Gainesville: Chintan V. Shah*. University of Florida-Health-Jacksonville: Vishal Jaikaransingh*. University of Illinois Hospital and Health Sciences System: Stephanie M. Toth-Manikowski*, Min J. Joo*, James P. Lash. University of Kentucky Medical Center: Javier A. Neyra*, Nourhan Chaaban, Madona Elias, Yahya Ahmad. University Medical Center of Southern Nevada: Rajany Dy*, Alfredo lardino, Elizabeth H. Au, Jill H. Sharma. University of Miami Health System: Marie Anne Sosa*, Sabrina Taldone, Gabriel Contreras, David De La Zerda, Alessia Fornoni, Hayley B. Gershengorn. University of Michigan: Salim S. Hayek*, Pennelope Blakely, Hanna Berlin, Tariq U. Azam, Husam Shadid, Michael Pan, Patrick O' Hayer, Chelsea Meloche, Rafey Feroze, Kishan J. Padalia, Abbas Bitar, Jeff Leya, John P. Donnelly, Andrew J. Admon. University of North Carolina School of Medicine: Jennifer E. Flythe*, Matthew J. Tugman, Emily H. Chang. University of Oklahoma Health Sciences Center: Brent R. Brown*. University of Pennsylvania Health System: Amanda K. Leonberg-Yoo*, Ryan C. Spiardi, Todd A. Miano, Meaghan S. Roche, Charles R. Vasquez University of Pittsburgh Medical Center: Amar D. Bansal*, Natalie C. Ernecoff, Sanjana Kapoor, Siddharth Verma, Huiwen Chen. University of Tennessee Health Science Center and Memphis VA Medical. Center/Methodist 
University Hospital - Csaba P. Kovesdy*, Miklos Z. Molnar*, Ambreen Azhar. University of Texas Southwestern Medical Center and Parkland Health and Hospital System: S. Susan Hedayati*, Mridula V. Nadamuni, Shani Shastri, Duwayne L. Willett. University of Vermont Larner College of Medicine: Samuel A.P. Short. University of Virginia Health System: Amanda D. Renaghan*, Kyle B. Enfield. University of Washington Medical Center: Pavan K. Bhatraju*, A. Bilal Malik. Vanderbilt University Medical Center: Matthew W. Semler. Washington University in St. Louis/Barnes Jewish Hospital: Anitha Vijayan*, Christina Mariyam Joy, Tingting Li, Seth Goldberg, Patricia F. Kao. Wellforce Health System: Lowell General Hospital - Greg L. Schumaker*, Tufts Medical Center-Nitender Goyal* , Anthony J. Faugno, Greg L. Schumaker, Caroline M. Hsu, Asma Tariq, Leah Meyer, Ravi K. Kshirsagar, Aju Jose, Daniel E. Weiner Westchester Medical Center: Marta Christov*, Savneek Chugh, Jennifer Griffiths, Sanjeev Gupta, Aromma Kapoor, Savneek Chugh. Yale School of Medicine: Perry Wilson,* Tanima Arora, Ugochukwu Ugwuowo.

* Site Principal Investigator

\section{Declarations}

\section{Funding}

This study is unfunded work.

\section{Conflicts of interest}

DEL received research support from BioPorto outside the submitted work. DMC reports grants and personal fees from NovoNordisk, personal fees from PLC medical, grants from Bioporto, personal fees from Fresenius, personal fees from AstraZeneca, grants and personal fees from Jannssen, grants and personal fees from Gilead, and personal fees from Merck, all outside the submitted work. AS reports personal fees from Horizon Therapeutics PLC, AstraZeneca, and CVS Caremark. SG is a scientific coordinator for the ASCEND trial (GlaskoSmithKline), outside the submitted work. KSM reports serving on the BREATHE Trial Steering Committee, funded by Roivant/Kinevant Sciences, outside the submitted work. BOG receives consulting fees from Sedana Medical outside the submitted work. The authors of the writing committee are supported by the following grants from the National Institutes of Health: K08GM134220 and R03AG060179 (SS); R01HL144566 and R01DK125786 (DEL); K23HL130648 (KSM); R37 Al102634 (MAH); F32DC017342 (SG); K23DK120811 (AS); K23HL143053 (MWS).

\section{Ethics approval and consent to participate}

The study was approved with a waiver of informed consent by the Institutional Review Board at each participating site.

\section{Consent for publication}

Not applicable.

\section{Availability of data and material}

The authors SS, SKB, and DEL take responsibility for the integrity of the data and the accuracy of the analysis and are willing to submit to external review of the data upon request.

\section{Code availability}

Analyses were performed using SAS software version 9.4 (SAS Institute), code available upon request.

\section{Authors' contributions}

SS, SKB, and DEL conceived the study, had full access to the data in the study, and take responsibility for the integrity of the data and accuracy of the analyses. SS, SKB, and DEL wrote the manuscript. WW, ALM, MAH, and DEL performed the statistical analyses. ALM, and DEL designed the figures. SS, SKB, SG, DEL, DMC, SC, SHM, VP, MA, AB, SSH, AS, KSM, TSJ, ALY, AG, JA, KMW, TS, and $\mathrm{HS}$ acquired the data. All the authors provided feedback on the protocol and critically revised and approved the final version of the manuscript.

\section{Publisher's Note}

Springer Nature remains neutral with regard to jurisdictional claims in published maps and institutional affiliations.

Received: 12 August 2020 Accepted: 4 December 2020

Published online: 2 February 2021

\section{References}

1. Johns Hopkins University \& Medicine-Coronavirus Resource Center. https ://coronavirus.jhu.edu/map.html. Accessed 29 Nov 2020

2. Bartlett RH, Ogino MT, Brodie D, McMullan DM, Lorusso R, MacLaren G, Stead CM, Rycus P, Fraser JF, Belohlavek J, Salazar L, Mehta Y, Raman L, Paden ML (2020) Initial ELSO guidance document: ECMO for COVID-19 patients with severe cardiopulmonary failure. ASAIO J 66(5):472-474. https://doi.org/10.1097/MAT.0000000000001173

3. MacLaren G, Combes A, Brodie D (2020) Saying no until the moment is right: initiating ECMO in the EOLIA era. Intensive Care Med 46(10):18941896. https://doi.org/10.1007/s00134-020-06185-1

4. Abrams D, Schmidt M, Pham T, Beitler JR, Fan E, Goligher EC, McNamee JJ, Patroniti N, Wilcox ME, Combes A, Ferguson ND, McAuley DF, Pesenti A, Quintel M, Fraser J, Hodgson CL, Hough CL, Mercat A, Mueller T, Pellegrino V, Ranieri VM, Rowan K, Shekar K, Brochard L, Brodie D (2020) Mechanical ventilation for acute respiratory distress syndrome during extracorporeal life support. Research and practice. Am J Respir Crit Care Med 201(5):514-525. https://doi.org/10.1164/rccm.201907-1283Cl

5. Combes A, Schmidt M, Hodgson CL, Fan E, Ferguson ND, Fraser JF, Jaber S, Pesenti A, Ranieri M, Rowan K, Shekar K, Slutsky AS, Brodie D (2020) Extracorporeal life support for adults with acute respiratory distress syndrome. Intensive Care Med. https://doi.org/10.1007/s00134-020-06290-1

6. Peek GJ, Mugford M, Tiruvoipati R, Wilson A, Allen E, Thalanany MM, Hibbert CL, Truesdale A, Clemens F, Cooper N, Firmin RK, Elbourne D (2009) Efficacy and economic assessment of conventional ventilatory support versus extracorporeal membrane oxygenation for severe adult respiratory failure (CESAR): a multicentre randomised controlled trial. Lancet 374(9698):1351-1363. https://doi.org/10.1016/s0140-6736(09)61069-2

7. Combes A, Hajage D, Capellier G, Demoule A, Lavoué S, Guervilly C, Da Silva D, Zafrani L, Tirot P, Veber B, Maury E, Levy B, Cohen Y, Richard C, Kalfon P, Bouadma L, Mehdaoui H, Beduneau G, Lebreton G, Brochard L, Ferguson ND, Fan E, Slutsky AS, Brodie D, Mercat A, EOLIA Trial Group, REVA, and ECMONet (2018) Extracorporeal membrane oxygenation for severe acute respiratory distress syndrome. N Engl J Med 378(21):19651975. https://doi.org/10.1056/NEJMoa1800385

8. Combes A, Peek GJ, Hajage D, Hardy P, Abrams D, Schmidt M, Dechartres A, Elbourne D (2020) ECMO for severe ARDS: systematic review and individual patient data meta-analysis. Intensive Care Med 46(11):2048-2057. https://doi.org/10.1007/s00134-020-06248-3

9. Li X, Guo Z, Li B, Zhang X, Tian R, Wu W, Zhang Z, Lu Y, Chen N, Clifford SP, Huang J (2020) Extracorporeal membrane oxygenation for coronavirus disease 2019 in Shanghai. China ASAIO J 66(5):475-481. https://doi. org/10.1097/MAT.0000000000001172

10. Zeng Y, Cai Z, Xianyu Y, Yang BX, Song T, Yan Q (2020) Prognosis when using extracorporeal membrane oxygenation (ECMO) for critically ill COVID-19 patients in China: a retrospective case series. Crit Care 24(1):148. https://doi.org/10.1186/s13054-020-2840-8

11. Henry BM, Lippi G (2020) Poor survival with extracorporeal membrane oxygenation in acute respiratory distress syndrome (ARDS) due to coronavirus disease 2019 (COVID-19): pooled analysis of early reports. J Crit Care 58:27-28. https://doi.org/10.1016/j.jcrc.2020.03.011

12. Sultan I, Habertheuer A, Usman AA, Kilic A, Gnall E, Friscia ME, Zubkus D, Hirose H, Sanchez P, Okusanya O, Szeto WY, Gutsche J (2020) The role of extracorporeal life support for patients with COVID-19: preliminary results from a statewide experience. J Card Surg. https://doi.org/10.1111/ jocs. 14583

13. Jacobs JP, Stammers AH, St Louis J, Hayanga JWA, Firstenberg MS, Mongero LB, Tesdahl EA, Rajagopal K, Cheema FH, Coley T, Badhwar V, Sestokas AK, Slepian MJ (2020) Extracorporeal membrane oxygenation in the treatment of severe pulmonary and cardiac compromise in COVID-19: experience with 32 patients. ASAIO J. https://doi.org/10.1097/MAT.00000 00000001185

14. Osho AA, Moonsamy P, Hibbert KA, Shelton KT, Trahanas JM, Attia RQ, Bloom JP, Onwugbufor MT, D'Alessandro DA, Villavicencio MA, Sundt TM, Crowley JC, Raz Y, Funamoto M (2020) Veno-venous extracorporeal membrane oxygenation for respiratory failure in COVID-19 patients: early experience from a major academic medical Center in North America. Ann Surg. https://doi.org/10.1097/SLA.0000000000004084

15. Falcoz PE, Monnier A, Puyraveau M, Perrier S, Ludes PO, Olland A, Mertes PM, Schneider F, Helms J, Meziani F, Group CT (2020) Extracorporeal membrane oxygenation for critically ill patients with COVID-19 related 
acute respiratory distress syndrome: worth the effort? Am J Respir Crit Care Med. https://doi.org/10.1164/rccm.202004-1370LE

16. Kon ZN, Smith DE, Chang SH, Goldenberg RM, Angel LF, Carillo JA, Geraci TC, Cerfolio RJ, Montgomery RA, Moazami N, Galloway AC (2020) Extracorporeal membrane oxygenation support in severe COVID-19. Ann Thorac Surg. https://doi.org/10.1016/j.athoracsur.2020.07.002

17. Mustafa AK, Alexander PJ, Joshi DJ, Tabachnick DR, Cross CA, Pappas PS, Tatooles AJ (2020) Extracorporeal membrane oxygenation for patients with COVID-19 in severe respiratory failure. JAMA Surg. https://doi. org/10.1001/jamasurg.2020.3950

18. Schmidt M, Hajage $D$, Lebreton G, Monsel A, Voiriot G, Levy D, Baron E, Beurton A, Chommeloux J, Meng P, Nemlaghi S, Bay P, Leprince P, Demoule A, Guidet B, Constantin JM, Fartoukh M, Dres M, Combes A (2020) Extracorporeal membrane oxygenation for severe acute respiratory distress syndrome associated with COVID-19: a retrospective cohort study. Lancet Respir Med. https://doi.org/10.1016/s2213-2600(20)30328-3

19. Barbaro RP, MacLaren G, Boonstra PS, I washyna TJ, Slutsky AS, Fan E, Bartlett RH, Tonna JE, Hyslop R, Fanning JJ, Rycus PT, Hyer SJ, Anders MM, Agerstrand CL, Hryniewicz K, Diaz R, Lorusso R, Combes A, Brodie D, Organization ELS (2020) Extracorporeal membrane oxygenation support in COVID-19: an international cohort study of the Extracorporeal Life Support Organization registry. Lancet. https://doi.org/10.1016/S0140 $-6736(20) 32008-0$

20. Gupta S, Hayek SS, Wang W, Chan L, Mathews KS, Melamed ML, Brenner SK, Leonberg-Yoo A, Schenck EJ, Radbel J, Reiser J, Bansal A, Srivastava A, Zhou Y, Sutherland A, Green A, Shehata AM, Goyal N, Vijayan A, Velez JCQ, Shaefi S, Parikh CR, Arunthamakun J, Athavale AM, Friedman AN, Short SAP, Kibbelaar ZA, Abu Omar S, Admon AJ, Donnelly JP, Gershengorn HB, Hernan MA, Semler MW, Leaf DE, Investigators STOP-COVID (2020) Factors associated with death in critically ill patients with coronavirus disease 2019 in the US. JAMA Intern Med. https://doi.org/10.1001/jamaintern med.2020.3596

21. Harris PA, Taylor R, Minor BL, Elliott V, Fernandez M, O'Neal L, McLeod L, Delacqua G, Delacqua F, Kirby J, Duda SN, Consortium R (2019) The REDCap consortium: building an international community of software platform partners. J Biomed Inform 95:103208. https://doi.org/10.1016/j. jbi.2019.103208

22. Rajagopal K, Keller SP, Akkanti B, Bime C, Loyalka P, Cheema FH, Zwischenberger JB, El Banayosy A, Pappalardo F, Slaughter MS, Slepian MJ (2020) Advanced pulmonary and cardiac support of COVID-19 patients: emerging recommendations from ASAIO-A "living working document." ASAIO J. https://doi.org/10.1097/MAT.0000000000001180

23. Ranieri VM, Rubenfeld GD, Thompson BT, Ferguson ND, Caldwell E, Fan E, Camporota L, Slutsky AS (2012) Acute respiratory distress syndrome: the Berlin definition. JAMA 307(23):2526-2533. https://doi.org/10.1001/ jama.2012.5669

24. Hernán MA, Sauer BC, Hernández-Díaz S, Platt R, Shrier I (2016) Specifying a target trial prevents immortal time bias and other self-inflicted injuries in observational analyses. J Clin Epidemiol 79:70-75. https://doi. org/10.1016/j.jclinepi.2016.04.014

25. Ferreira FL, Bota DP, Bross A, Melot C, Vincent JL (2001) Serial evaluation of the SOFA score to predict outcome in critically ill patients. JAMA 286(14):1754-1758. https://doi.org/10.1001/jama.286.14.1754

26. Vincent JL, de Mendonca A, Cantraine F, Moreno R, Takala J, Suter PM, Sprung CL, Colardyn F, Blecher S (1998) Use of the SOFA score to assess the incidence of organ dysfunction/failure in intensive care units: results of a multicenter, prospective study. Working group on "sepsis-related problems" of the European Society of Intensive Care Medicine. Crit Care Med 26(11):1793-1800. https://doi.org/10.1097/00003246-19981 1000-00016

27. Schmidt M, Bailey M, Sheldrake J, Hodgson C, Aubron C, Rycus PT, Scheinkestel C, Cooper DJ, Brodie D, Pellegrino V, Combes A, Pilcher D (2014) Predicting survival after extracorporeal membrane oxygenation for severe acute respiratory failure. The Respiratory Extracorporeal Membrane Oxygenation Survival Prediction (RESP) score. Am J Respir Crit Care Med 189(11):1374-1382. https://doi.org/10.1164/rccm.201311-20230C

28. COVID-ICU Group on behalf of the REVA Network and the COVID-ICU Investigators (2020) Clinical characteristics and day-90 outcomes of 4244 critically ill adults with COVID-19: a prospective cohort study. Intensive Care Med. https://doi.org/10.1007/s00134-020-06294-x

29. Zangrillo A, Biondi-Zoccai G, Landoni G, Frati G, Patroniti N, Pesenti A, Pappalardo F (2013) Extracorporeal membrane oxygenation (ECMO) in patients with $\mathrm{H} 1 \mathrm{~N} 1$ influenza infection: a systematic review and metaanalysis including 8 studies and 266 patients receiving ECMO. Crit Care 17(1):R30. https://doi.org/10.1186/cc12512

30. Sukhal S, Sethi J, Ganesh M, Villablanca PA, Malhotra AK, Ramakrishna H (2017) Extracorporeal membrane oxygenation in severe influenza infection with respiratory failure: a systematic review and meta-analysis. Ann Card Anaesth 20(1):14-21. https://doi.org/10.4103/0971-9784.197820

31. Admon AJ, Donnelly JP, Casey JD, Janz DR, Russell DW, Joffe AM, Vonderhaar DJ, Dischert KM, Stempek SB, Dargin JM, Rice TW, Iwashyna TJ, Semler MW (2019) Emulating a novel clinical trial using existing observational data predicting results of the PreVent study. Ann Am Thorac Soc 16(8):998-1007. https://doi.org/10.1513/AnnalsATS.201903-241OC

32. Dickerman BA, Garcia-Albeniz X, Logan RW, Denaxas S, Hernan MA (2019) Avoidable flaws in observational analyses: an application to statins and cancer. Nat Med 25(10):1601-1606. https://doi.org/10.1038/s4159 1-019-0597-x

33. Petito LC, Garcia-Albeniz X, Logan RW, Howlader N, Mariotto AB, Dahabreh IJ, Hernan MA (2020) Estimates of overall survival in patients with cancer receiving different treatment regimens: emulating hypothetical target trials in the surveillance, epidemiology, and end results (SEER)medicare linked database. JAMA Netw Open 3(3):e200452. https://doi. org/10.1001/jamanetworkopen.2020.0452

34. Gupta S, Wang W, Hayek SS, Chan L, Mathews KS, Melamed ML, Brenner SK, Leonberg-Yoo A, Schenck EJ, Radbel J, Reiser J, Bansal A, Srivastava A, Zhou Y, Finkel D, Green A, Mallappallil M, Faugno AJ, Zhang J, Velez JCQ, Shaefi S, Parikh CR, Charytan DM, Athavale AM, Friedman AN, Redfern RE, Short SAP, Correa S, Pokharel KK, Admon AJ, Donnelly JP, Gershengorn HB, Douin DJ, Semler MW, Hernán MA, Leaf DE (2020) Association between early treatment with tocilizumab and mortality among critically ill patients with COVID-19. JAMA Intern Med. https://doi.org/10.1001/jamai nternmed.2020.6252

35. van Walraven C, Bennett C, Forster AJ (2011) Administrative database research infrequently used validated diagnostic or procedural codes. J Clin Epidemiol 64(10):1054-1059. https://doi.org/10.1016/j.jclin epi.2011.01.001

36. MacLaren G, Combes A, Brodie D (2020) What's new in ECMO for COVID19? Intensive Care Med. https://doi.org/10.1007/s00134-020-06284-z

37. Guervilly C, Prud'homme E, Pauly V, Bourenne J, Hraiech S, Daviet F, Adda M, Coiffard B, Forel JM, Roch A, Persico N, Papazian L (2019) Prone positioning and extracorporeal membrane oxygenation for severe acute respiratory distress syndrome: time for a randomized trial? Intensive Care Med 45(7):1040-1042. https://doi.org/10.1007/s00134-019-05570-9

38. Schmidt M, Pham T, Arcadipane A, Agerstrand C, Ohshimo S, Pellegrino V, Vuylsteke A, Guervilly C, McGuinness S, Pierard S, Breeding J, Stewart C, Ching SSW, Camuso JM, Stephens RS, King B, Herr D, Schultz MJ, Neuville M, Zogheib E, Mira JP, Roze H, Pierrot M, Tobin A, Hodgson C, Chevret S, Brodie D, Combes A (2019) Mechanical ventilation management during extracorporeal membrane oxygenation for acute respiratory Distress Syndrome. An international multicenter prospective cohort. Am J Respir Crit Care Med 200(8):1002-1012. https://doi.org/10.1164/rccm.20180 6-1094OC 